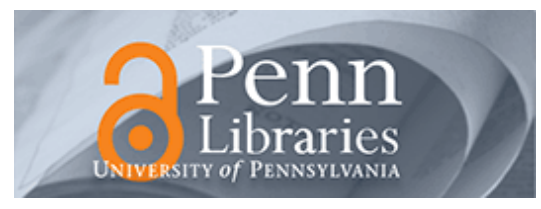

University of Pennsylvania

ScholarlyCommons

Health Care Management Papers

Wharton Faculty Research

3-2011

\title{
Physician Division of Labor and Patient Selection for Outpatient Procedures
}

Guy David

University of Pennsylvania

Mark. D. Neuman

University of Pennsylvania

Follow this and additional works at: https://repository.upenn.edu/hcmg_papers

Part of the Health Economics Commons, Health Services Research Commons, Medical Education Commons, and the Other Public Health Commons

\section{Recommended Citation}

David, G., \& Neuman, M. D. (2011). Physician Division of Labor and Patient Selection for Outpatient Procedures. Journal of Health Economics, 30 (2), 381-391. http://dx.doi.org/10.1016/

j.jhealeco.2010.11.007

This paper is posted at ScholarlyCommons. https://repository.upenn.edu/hcmg_papers/110

For more information, please contact repository@pobox.upenn.edu. 


\title{
Physician Division of Labor and Patient Selection for Outpatient Procedures
}

\author{
Abstract \\ Little is known about the ability of incentives to influence decisions by physicians regarding choices of \\ settings for care delivery. In the context of outpatient procedural care, the emergence of freestanding \\ ambulatory surgery centers (ASCs) as alternatives to hospital-based outpatient departments (HOPDs) \\ creates a unique opportunity to study this question. We advance a model where physicians' division of \\ labor between ASCs and HOPDs affects the medical complexity of patients treated in low-acuity settings \\ (i.e. ASCs). Analyses of outpatient surgical procedure data show that physicians working exclusively in \\ low-acuity settings (i.e. ASCs) treat patients of significantly higher medical complexity in these settings \\ than do physicians who also practice in higher-acuity settings (i.e. HOPDs). This discrepancy shrinks with \\ increasing procedural risk and with increasing distance between ASCs and acute care hospitals.

\section{Keywords} \\ outpatient care, patient selection, physician behavior \\ Disciplines \\ Health Economics | Health Services Research | Medical Education | Other Public Health
}




\title{
Physician Division of Labor and Patient Selection for Outpatient Procedures
}

\author{
Guy David \\ The Wharton School \\ University of Pennsylvania \\ Mark D. Neuman \\ School of Medicine \\ University of Pennsylvania
}

May 2010

\begin{abstract}
Little is known about the effect of incentives on physicians' choices of settings for medical procedures. We advance a model where physicians' division of labor between ambulatory surgery centers (ASCs) and hospital-based outpatient departments (HOPDs) affects the medical complexity of patients treated in low-acuity settings (i.e. ASCs). Analyses of outpatient surgical procedure data show that physicians working exclusively in low-acuity settings (i.e. ASCs) treat patients of significantly higher medical complexity in these settings than do physicians who also practice in higher-acuity settings (i.e. HOPDs).This discrepancy shrinks with increasing procedural risk and with increasing distance between ASCs and acute care hospitals.
\end{abstract}

JEL Classification: I11; I12; D8

Keywords: Outpatient Care; Patient Selection; Physician Behavior

We thank David Abrams, Charles Branas, Lee Fleisher, Alex Gelber, Amy Hillier, Andrea Millman, Daniel Polsky, John Rizzo, Sandy Schwartz, and Jeff Silber for their helpful comments. Erin Quinn, Phil Saynisch, and Victoria Perez provided excellent research assistance. Financial support from the Leonard Davis Institute of Health Economics, University of Pennsylvania is gratefully acknowledged. 


\section{Introduction}

The motives and ability of physicians to influence the medical services used by their patients has received much attention in the health economics literature (Arrow, 1963; McGuire, 2000). Seminal work in this area has focused on demand inducement, where financial incentives may increase the quantity of services recommended and delivered by physicians beyond the point at which the medical benefits of such services justify their costs (Evans, 1974; McGuire and Pauly, 1991; Labelle et al., 1994; Gruber and Owings, 1996). Prior work on referrals by physicians for office- versus hospital-based care has highlighted the effects of financial incentives on decisions regarding the utilization of resources for the care of acute conditions (Marinoso and Jelovac, 2003; Blomqvist and Léger, 2005; Bain and Morrisey, 2007; David and Helmchen, 2010). However, little attention has been paid to incentives that may influence decisions regarding the choice of setting for otherwise identical medical procedures in cases where such choices may influence patient outcomes.

In the context of outpatient care in the United States, decisions regarding care settings are of increasing importance due to the rapid growth over time in alternatives to traditional hospital-based outpatient departments (HOPDs) for the provision of diagnostic and therapeutic procedures. In particular, patient visits to freestanding ambulatory surgery centers (ASCs), facilities physically separate from acute-care hospitals, increased by 300 percent between 1996 and 2006 (Cullen, Hall, \& Golosinskiy, 2009) with the number of ASCs in the U.S. growing from 240 in 1983 to 5,174 by 2008 (Medicare Payment Advisory Commission, 2009). The increased prevalence of ASCs has created distinct responsibilities for physicians related to the choice of care setting (Lynk and Longley, 2002). Prior approaches to patient selection in procedural care have focused exclusively on balancing the anticipated benefits of a given procedure with the probability of a complication as determined by patient and procedural factors (Bryson et al., 2004). As ASCs and HOPDs differ in their access to hospital care, physicians must also decide on the appropriate care setting based on the probability of a surgical complication and the accessibility to hospital services that may be critical to the management of such a complication.

The decision of a physician regarding the location of care for a patient of a given risk profile should therefore be sensitive to incentive structures that vary according to patterns of physician division-of-labor. More specifically, we identify two groups of ASC physicians who differ in their access to HOPDs, distinguishing "splitters," those who perform outpatient procedures 
at both ASCs and HOPDs, from "non-splitters," those who work exclusively at ASCs. We advance a simple model of physician agency, where physicians derive utility from both clinical appropriateness and monetary rewards, to show that the opportunity cost of providing care in one location versus another depends on the physician's division of labor. Non-splitters face a relatively greater opportunity cost of referring high-risk patients to HOPD-based care. As a consequence, splitters would deliver care to higher-risk patients overall, but to lower-risk patients within ASCs, compared to their non-splitter counterparts. The first prediction stems from the appropriateness of HOPDs for patients with elevated surgical risk. The second prediction stems from the higher profitability of a self-referral compared with an out-referral. Moreover, as the consequences of surgical complications at ASCs may depend on their distance from the nearest acute-care hospital, our model demonstrates that, while patient-level risk would decrease with increasing distance from hospital care, differences in risk selection between physician types would diminish as a function of distance.

As a test of our model's predictions, we examine the outpatient surgical risk profiles of 1,326,337 ASC and 464,568 HOPD patient visits for two common outpatient procedures performed in Florida between 2004 and 2007. We use the patientlevel Charlson Comorbidity Index, (Charlson et al, 1987; Quan et al, 2005), a common measure of medical severity, to quantify the patient-level operative risk observable to the physician. We use a rich set of area, facility, patient, physician, and procedure variables to study the relationship between physician splitter status and patients' setting selection on risk. As risk selection behaviors may be endogenous to splitter status, we instrument for splitter status using an indicator variable that equals one if the physician completed medical training in Florida and zero if the physician completed medical training in a different state in the U.S. Medical training in Florida is highly correlated with retaining admitting privileges in hospital outpatient departments, which we hypothesize may be due to preservation of professional networks and affiliations established at the time of training. Hence, we observe a higher likelihood of splitter status among former instate trainees. At the same time, controlling for foreign medical graduate status, completion of medical education in Florida is likely to be uncorrelated with other variables affecting patient selection on risk, as we hypothesize the quality of medical training within Florida will be similar to the average quality of training available in other U.S. states. 
As expected, we find that, compared to non-splitters, splitters treat more medically complex patients overall, with the most complex patients being concentrated in the HOPD setting; within ASCs, we find risk profiles to be lower among patients treated by splitters when compared to those treated by non-splitters. We find case selection by splitters to be related not only to the site of care (i.e., ASC vs. HOPD), but also to the distance between the ASC and the nearest hospital. Finally, we find a growing similarity in case-level risk for non-splitters and splitters as the distance between the ASC and the nearest acute-care hospital increases.

All results are consistent for cross-sectional regressions and for those using county fixed-effects, which account for potential confounding of the relationship between splitter status and risk selection by variation across individual ASCs in given geographical regions. Our results persist under our instrumental variable strategy, which account for potential endogeneity of risk selection to splitter or non-splitter status. Further robustness checks include the use of alternate definitions of splitting, the use of alternative dependent variables, and alternate instruments.

Our findings are consistent with the argument that patient selection by physicians for care in ASCs is sensitive to differences in the opportunity cost of sending a patient to the alternate, more resource-intensive setting of the HOPD. This effect persists despite adjustment for procedure factors, secular time, physician factors, county fixed effects, and potential omitted variable bias. Such observations provide a clear illustration of deviation from perfect agency in medical decision making, which extends beyond the quantity of care.

The paper proceeds as follows: section 2 presents a simple model of physician choice, in which asymmetric information regarding surgical risk and variation in division of labor for providers dictates the site of care for patients. Section 3 describes the data and estimation, section 4 discusses the results, and section 5 concludes.

\section{Conceptual Framework}

In this section we model a "downstream" medical decision, in which patients have already been determined to need a given procedure. Rather than exploring induced utilization, as much past research has, we focus on the setting of care and the 
context in which that procedure is provided. While physicians in our model act as agents for patients in that they help patients make decisions regarding the site of care, they also posses superior medical information regarding each patient's risk of surgical complications and hence the most appropriate site for care. Information asymmetries allow physicians in our model to act as imperfect agents for their patients, deriving utility from both the clinical appropriateness as well as the monetary rewards associated with each setting. In particular, the opportunity cost of out-referral in the case of nonsplitters exceeds the cost of self-referral in the case of splitters, as non-splitters face lost income from the patients they refer out.

Patients generate a value, $\mathrm{V}(\theta)$, from receiving an outpatient procedure as a function of severity level, $\theta$ (with large values of $\theta$ corresponding to higher surgical risk). Assume that the distribution from which surgical risk is drawn is bounded by the interval $\left[\theta_{L}, \theta_{H}\right]$. For simplicity, we assume that information asymmetry between surgeons and patients are such that patients cannot observe $\theta^{1}$ Nevertheless, all patients have $\theta_{\mathrm{L}}<\theta<\theta_{\mathrm{H}}$, such that their corresponding value of surgery exceeds the value of not getting the procedure at all. Classic demand inducement would suggest the potential for service provision to patients for whom the benefit from the intervention is extremely low (i.e. $\theta<\theta_{\mathrm{L}}$ ) and/or patients for whom the surgical risk associated with the intervention is extremely high (i.e. $\theta>\theta_{H}$ ). This model ignores such extensive margins expansions/deviations, as it focuses on incentives that influence decisions regarding the (intensive margins) choice of setting for medical care. ${ }^{2}$ To the extent that the choice of setting is driven, in part, by non-clinical grounds, it constitutes a deviation from perfect agency that may influence patient outcomes through inappropriate patient risk selection.

Procedures in the interval $\left[\theta_{L}, \theta_{C}\right]$, where $\theta_{C}<\theta_{H}$, are clinically appropriate for ASCs while all procedures in the interval [ $\theta_{L}$, $\left.\theta_{H}\right]$ are appropriate for HOPDs. The cost to a physician of performing a procedure in an ASC is lower than the cost of performing the same procedure in a HOPD, (Casalino LP, Devers KJ \& Brewster LR, 2003) i.e. $c^{A}(\theta)<c^{H}(\theta)$, where the

\footnotetext{
${ }^{1}$ The model's results are robust to the assumption that patients can imperfectly observe $\theta$.

${ }^{2}$ Alternatively, we can define $\theta_{L}$ to be zero surgical risk (i.e. no $\theta<\theta_{L}$ ), and $\theta_{H}$ to be sufficiently high, such that no physician would choose to operate on a patient with such elevated surgical risk.
} 
cost is monotonically increasing in surgical risk. The payment for the procedure is fixed at $p$. Hence, physician profit margins are higher at ASCs.

Physicians maximize utility, $U(\theta, s)$ which is influenced by the patient's surgical risk, $\theta$, and the setting of care (ASC or HOPD), $s$. We assume that all physicians have the ability to access an ASC but have a fixed cost, $F$, levied on them if they choose to maintain a split practice (i.e. become a splitter). This fixed cost is physician specific, as it stems from the time cost of operating in two facilities and the administrative costs of maintaining admitting privileges in HOPD. ${ }^{3}$ Since profit margins are higher at ASCs, when $\theta \leq \theta_{C}$ the surgeon will always decide to operate in an ASC and her utility would equal $U(\theta)=p-c^{A}(\theta)$. However, when $\theta>\theta_{C}$ the non-splitter surgeon will choose to operate in an ASC only if the profit margins in the ASC, $p-c^{A}(\theta)$, outweigh the disutility from deviating from the clinically appropriate for ASCs, described as a quadratic loss function, $\alpha \cdot\left(\theta-\theta_{C}\right)^{2}$, where $\alpha$ measures the value (or weight) placed on this deviation. $\alpha$ could be thought of as the degree of risk attributable to the procedure itself, or, alternatively, $\alpha$ could be thought of as the distance between the ASC and the nearest emergency department. ${ }^{4}$ If $\alpha=0$ the ASC has full access to backup capabilities or provides a procedure with zero risk to the patient and therefore there is no disutility from treating patients with higher surgical risk. Equation (1) provides the non-splitter surgeon's utility by a patient's surgical risk and setting:

$$
U(\theta, s)=\left\{\begin{array}{ccccc}
p-c^{A}(\theta) & \text { if } & \theta \leq \theta_{C} & \text { and } & s=\text { ASC } \\
p-c^{A}(\theta)-\alpha \cdot\left(\theta-\theta_{C}\right)^{2} & \text { if } & \theta>\theta_{C} & \text { and } & s=\text { ASC } \\
0 & \text { if } & \theta>\theta_{C} & \text { and } & s=H O P D
\end{array}\right.
$$

Similarly, when $\theta>\theta_{C}$ the splitter surgeon will choose to operate in an ASC only if the relatively higher margins in the ASC compared with a HOPD, $c^{H}(\theta)-c^{A}(\theta)$, outweigh the disutility from deviating from the clinically appropriate for ASCs,

\footnotetext{
${ }^{3}$ While legal statute disallows denial of hospital operating privileges to a physician on the basis of ASC affiliation or ownership, reports of efforts to deny privileges for this reason suggest that the choice to operate in an ASC may come with varying time and psychic costs for hospital physicians (for additional discussion see Lynk and Longley, 2002).

${ }^{4}$ Quadratic loss functions generally represent the economic cost or regret associated with a deviation from a set target, such as the level of medically appropriate care (for additional discussion see David and Helmchen, 2010).
} 
described as a quadratic loss function scaled by distance, $\alpha \cdot\left(\theta-\theta_{C}\right)^{2}$. Equation (2) provides the splitter surgeon's utility by a patient's surgical risk and setting:

$$
U(\theta, s)=\left\{\begin{array}{ccccc}
p-c^{A}(\theta) & \text { if } & \theta \leq \theta_{C} & \text { and } & s=\text { ASC } \\
p-c^{A}(\theta)-\alpha \cdot\left(\theta-\theta_{C}\right)^{2} & \text { if } & \theta>\theta_{C} & \text { and } & s=A S C \\
p-c^{H}(\theta) & \text { if } & \theta>\theta_{C} & \text { and } & s=H O P D
\end{array}\right.
$$

For splitters, the level of surgical risk, $\theta_{\mathrm{S}}$, above which a patient will be treated in a HOPD is the solution to the following condition: $\alpha \cdot\left(\theta_{S}-\theta_{C}\right)^{2}=c^{H}\left(\theta_{S}\right)-c^{A}\left(\theta_{S}\right)$. For non-splitters, the level of surgical risk, $\theta_{\mathrm{NS}}$, above which a patient will out referred for surgery in a HOPD is the solution to the following condition: $\alpha \cdot\left(\theta_{N S}-\theta_{C}\right)^{2}=p-c^{A}\left(\theta_{N S}\right)$. Since $p>c^{H}(\theta)$ for any level of surgical risk, the cutoff point of patient risk chosen by a splitter for self-referral to the HOPD is lower than that for out-referral chosen by a non-splitter. The case of the non-splitter is similar to Blomqvist and Léger (2005) where patients perceive their health status within broad intervals, and as a result, primary care physicians have an incentive to understate severity, in order to prevent having to refer patients out to specialists. Moreover, the cutoff point for surgical risk chosen by both splitters and non-splitters exceeds the clinically desired one. That is, $\theta_{C}<\theta_{S}<\theta_{N S}$.

Figure 1 summarizes these results. The solid line maps the level of surgical risk to the utility of a non-splitter (i.e. a combination of the first and second expressions in Equations (1) and (2)). The dotted line maps the level of surgical risk to the utility of from treating a patient in HOPD (i.e. the third expression in Equation (2)). Hence, the splitter's utility function is the external envelope (i.e. the solid line up to $\theta_{\mathrm{C}}$ and the dotted line from $\theta_{\mathrm{C}}$ to $\theta_{H}$ ). The area of interest is the grey area (between $\theta_{\mathrm{S}}$ and $\theta_{\mathrm{NS}}$ ) where patients seen by a splitter surgeon would be treated in a HOPD while patients seen by a nonsplitter surgeon would be treated in an ASC. Based on clinical experience, we assume that patients do not exhibit preferences for splitters. 
Additionally, this figure suggests that patients treated by splitters in HOPD are of markedly higher risk, as they include patients with surgical risk at the interval $\left[\theta_{N S}, \theta_{H}\right]$, which is out referred by non-splitters. Finally, since $\theta_{\mathcal{C}}<\theta_{S}$, even surgeons with split practice choose a risk cutoff above the clinically desired level, $\theta_{\mathrm{C}}$, as they also respond to incentives and prefer to treat patients with surgical risk between $\theta_{\mathrm{C}}$ and $\theta_{\mathrm{S}}$ in ASCs. While the first two predictions can be tested in the data, the third prediction requires an objective measure of $\theta_{c}$, which cannot be calculated using administrative data and requires detailed patient chart data.

Note that if patients seen by surgeon $i$, faced with fixed splitting costs, $F_{\mathrm{i}}$, are distributed uniformly along the interval $\left[\theta_{S}\right.$, $\left.\theta_{H}\right]$, splitting will occur if:

$$
\int_{\theta_{S}}^{\theta_{N S}}\left(p-c^{A}(\theta)-\alpha \cdot\left(\theta-\theta_{C}\right)^{2}\right) d \theta<\int_{\theta_{S}}^{\theta_{H}}\left(p-c^{H}(\theta)\right) d \theta-F_{i} .
$$

As $\alpha$, the distance between the ASC and the nearest emergency department, increases the weight placed on deviation from $\theta_{C}$ which in turn lowers both $\theta_{S}$ and $\theta_{N S}$. Additionally, $\theta_{N S}-\theta_{S}$ decreases with $\alpha$, such that there is growing similarity between splitters and non-splitters as the distance between ASCs and hospitals increases. ${ }^{5}$

\section{Data and Sample}

We examined records from the Florida Agency for Health Care Administration's (AHCA) 2005-2007 Ambulatory Patient Databases (APD), which includes visit-level data from all freestanding ambulatory surgical centers and short-term acute care hospitals in the state of Florida. The public use data file contains information on 33 variables, including year and quarter of data collection, facility name, operating physician license number, type of facility, patient age, gender, residential ZIP code, principal payer, principal and up to nine secondary procedures performed, principal and up to nine secondary diagnoses, and patient discharge status. Procedure coding uses Current Procedure Terminology (CPT) coding and the International Classification of Disease-9 (ICD-9) coding system. To quantify pre-procedure patient risk, we calculated the Charlson Comorbidity Index, a common non-negative integer measure of medical severity, for each patient based on ICD-9-CM

\footnotetext{
${ }^{5}$ A higher $\alpha$, implies greater benefits from splitting, however, the greater the distance between an ASC and a hospital is for a surgeon, so is the fixed costs, $F_{\mathrm{i}}$, associated with splitting. Therefore, this model cannot predict changes in the likelihood of splitting that occur as a function of ASCs-to-hospital distance.
} 
diagnosis codes contained in the APD, using algorithms described by Quan et al. (2005). While the Charlson Index does not include patient age, it is highly correlated with patient age; we thus report results from models with and without age as a regressor.

Data regarding the location of medical school training were collected from the Florida Department of Health's physician information database, to which all Florida physicians are required by law to submit data regarding medical training. ${ }^{6}$ Data were collected on the state in which medical school was completed, foreign medical graduate status, graduation year, and completion of subspecialty postgraduate training.

To identify hospitals that may have been available to provide care to an adult procedural outpatient for each calendar quarter, we used the AHCA inpatient data file, which includes visit-level data on patient, provider, facility, and encounter variables, including variables that identify the source of admission (e.g. Emergency Department, physician referral, hospital transfer). We classified a hospital as "open" in a given quarter if it reported one or more discharges of patients 18 years or older whose source of admission was listed as "Emergency Room." We excluded specialty surgical hospitals and facilities providing exclusively pediatric, psychiatric, or rehabilitation care, as we considered such facilities to be unlikely to offer emergency services to procedural outpatients. We verified our results using web searches and AHCA directories.

We obtained ASC and hospital addresses from AHCA directories, and calculated the point-to-point (Euclidean) distance between each location where a procedure occurred and the nearest acute-care hospital in operation at that time. Note that since HOPDs are located in hospitals, all HOPD-to-ED distances are zero. We focused exclusively on common gastrointestinal endoscopy procedures, namely upper endoscopy (UE) and colonoscopy, for patients 18 years of age or older. ${ }^{7}$ We examined gastrointestinal endoscopies for three reasons: first, UE and colonoscopy are two of the three most

\footnotetext{
${ }^{6}$ All searches were conducted between August 3, 2009 and September 28, 2009, using physician license numbers to identify individual providers. The website used is: http://ww2.doh.state.fl.us/IRMOOPRAES/PRASLIST.ASP. Facilities were located by street addresses on maps made available by the U.S. Census Bureau, and locations were verified by comparison of ZIP codes between facility addresses and mapped points.

7 Upper endoscopy (UE) and colonoscopy are identified by presence of any of the following principal CPT codes: $43234,43235,43239$, 43250, 43251, 43255, 43258, 43241, 43243, 43244, 43245, 43246, 43247, 43248, and 43249 (UE); and 45378, 45379, 45380, 45381, $45382,45383,45384$, and 45385 (colonoscopy).
} 
common ambulatory procedures performed in the U.S. (Cullen, Hall, \& Golosinskiy, 2009) ${ }^{8}$ Second, these two procedures are performed at high rates in both ASCs and HOPDs, increasing the likelihood that scenarios may exist in which a patient may be referred either to an ASC or an HOPD based on pre-procedure risk factors. Third, these procedures are typically provided by gastroenterologists, a group of specialized physicians with similar amounts of training, allowing for comparisons of decision-making among physicians with comparable levels of training. Finally, we duplicated all analyses using a subset of our data, restricted to patients undergoing screening colonoscopy for colon cancer. ${ }^{9}$ The American Cancer Society guidelines recommend initiation of colon cancer screening in adults at age 50. Focusing on a routine, lowcomplexity procedure with a uniform indication mitigates concerns about procedural mix.

Physicians were defined as splitters or non-splitters based on the fraction of all outpatient procedural cases performed over the study period at ASCs. While regression analyses considered only UE and colonoscopy or screening colonoscopy alone, our definitions of division-of-labor examined all outpatient procedures to obtain the most comprehensive description of physician access to ASCs and HOPDs. We defined splitters as those physicians for whom at least $5 \%$ and up to $95 \%$ of all outpatient cases were performed at ASCs. ${ }^{10}$ We define non-splitters as those for who over $99 \%$ of all outpatient cases were performed at ASCs. ${ }^{11}$ While we employed a definition of splitting based on all cases performed over the three year period, we also examined the percentage of cases performed by each physician at an ASC by calendar quarter to rule out misclassification of physicians switching from an all-ASC (or HOPD) to an all-HOPD (or ASC) practice as splitters. We excluded low volume physicians, defined as providing fewer than 150 procedures over the entire study period.

By these definitions, we classified 47 physicians as non-splitters and 739 as splitters. The average splitter in our sample performed $68 \%$ of cases in an ASC and $32 \%$ in an HOPD. The number of total procedures observed per physician did not

\footnotetext{
${ }^{8}$ The third category of ambulatory procedure is lens and cataract surgery, which involves no surgical risk and is rarely performed in hospital outpatient departments.

${ }^{9}$ Screening colonoscopies were identified by presence of one of three principal ICD-9-CM diagnosis codes (V76.41, V76.50, or V76.51) in any patient aged 50 years or older.

${ }^{10}$ Our results are robust to using different window definitions.

${ }^{11}$ While our main analysis excludes physicians locating between $95 \%$ and $99 \%$ of their practice at ASCs, all results are robust to alternative definitions of non-splitters as all physicians with over $95 \%$ of their practice at an ASC.
} 
differ significantly between groups, with the average splitter performing 67.6 cases per month (ASCs and HOPDs), and the average non-splitter performing 59.7 cases per month (ASCs only).

We identified 192 ASCs and 196 HOPDs in our dataset. 57.8 percent of ASCs where less than a mile away from an acute hospital, with fewer than $1 \%$ of ASCs located on that hospital campus. The average distance from acute care hospitals for the remaining ASCs was 2.8 miles, with the greatest distance between an ASC and the nearest hospital being 12.8 miles. Excluding cases performed by physicians working only in HOPDs, which were not included in our regression analyses, the average ASC had more visits per month than did the average HOPD (190.5 vs. 72.3 ), despite a lower average number of physicians at ASCs versus HOPDs (6.41 vs. 9.35).

Table 1 reports summary statistics for patients cared for by splitter and non-splitter physicians for both the full patient sample and for a sample undergoing screening colonoscopy only. Medical complexity was highest among patients receiving care in HOPDs. Within ASCs, non-splitters cared for patients of greater medical severity than did splitters. Significant differences existed between patient groups for other patient-level characteristics, including race, insurance, and performance of secondary procedures within the visit. Notably, in both samples, non-splitters delivered care to patients of greater average age; we found this to be fully accounted for by distributional effects, as non-splitters delivered care to a greater proportion of patients over age 65 than did non-splitters.

The distribution of patient-level risk across care settings by splitters and non-splitters is further depicted in Figure 2. Among patients receiving care from splitters, average operative risk, as measured by the Charlson Comorbidity index, is more than eight times greater for those treated in HOPDs compared with those treated in ASCs. Comparing patients treated within ASCs by splitters and non-splitters, average Charlson Score is consistently greater for those patients treated by nonsplitters. Comparing the full sample of patients (upper panel of Figure 2) with the sample restricted to screening colonoscopies only (lower panel of Figure 2) we find consistent patterns for the two samples. Differences in Charlson scores for splitters and non-splitters is greater for screening colonoscopy compared with the full sample (both for the full sample, 
and in samples restricted to patients below 65 years of age and patient aged 65 and over). Similarly, these differences are greater for patient aged 65 and over compared with patients below 65 years of age (regardless of the set of procedures).

\section{Empirical Models}

Broadly speaking we use two mutually exclusive strategies: we use variation in physician type (splitters vs. non splitters) to study risk selection in ASCs, and use variation in settings type (ASCs vs. HOPDs) to study risk selection by physicians who operate in both settings (i.e. within splitters). ${ }^{12}$ The latter analysis is important for establishing the notion that a physician with access to both an ASC and an HOPD would schedule patients with higher medical complexity at the HOPD.

To determine whether patients' surgical risks vary systematically across splitters and non-splitters, the following model is estimated:

(4) $\quad Y_{i, j, k, t}=\beta_{S} \cdot S_{j, k}+\theta \cdot X_{i, j, k, t}+\gamma \cdot P_{i}+\delta \cdot M_{j}+\phi_{t}+\mu_{k}+\varepsilon_{i, j, k, t}$, where

$Y_{i, j, k, t}$ corresponds to the Charlson Comorbidity Index score for patient $i$, physician $j$, county $k$, in period $t$. The coefficient, $\beta_{S}$, on the splitter variable, $S_{j, k}$, captures the extent to which splitters select patients with lower (or higher) surgical risk at ASCs. $X_{i, j, k, t}$ is a vector of specific encounter characteristics, including insurance status, principal CPT code, and presence of additional CPT codes to indicate higher levels of procedural complexity. $P_{i}$ is a vector of patient characteristics; $M_{j}$ is a vector of physician characteristics, including years in practice, presence of fellowship-level training in gastroenterology, and graduation from a U.S.-based medical school. $\phi_{t}$ are time fixed-effects, corresponding to the twelve quarters, and $\mu_{k}$ are county fixed-effects. Finally, $\varepsilon_{i, j, k, t}$ is an error term (results are reported in Table 2).

\footnotetext{
${ }^{12}$ Note that a simple difference-in-difference approach, looking across physician types and setting type is not feasible since non-splitters operate solely in ASCs.
} 
As discussed in the previous section, the Charlson Comorbidity score is a non-negative integer measure of medical severity. The bulk of patients in our data have a Charlson score of zero, and therefore this severity measure exhibits overdispersion (i.e. the conditional variance exceeds the conditional mean). To address this issue we use negative binomial models, zeroinflated models, and a matching strategy to balance our sample across high and low surgical risk patients using one-to-one nearest neighbor matching along all observable, patient-level, dimensions.

Our study will directly address two important sources of bias in assessing differences in risk selection across these two physician groups (splitters and non-splitters). First, the effect of variation across geographical areas may confound the relationship between splitter status and patient risk profiles. For example, if non-splitters tend to work in ASCs located in neighborhoods with older or higher-risk patients, non-splitters may appear to take on more risks. Similarly, as ASC's are located at varying distances from acute-care hospitals, variation may exist in the time required to transport patients to emergency care resources in the event of a complication. To address these potential confounding effects, we will use county fixed-effects analyses to compare splitters and non-splitters within a given area.

Second, selection of patients based on risk may be endogenous to splitter or non-splitter status. For example, if nonsplitters are less risk-averse than splitter physicians, or more highly skilled at providing care in ASC, patient risk profiles and splitting status could be considered to relate to unobserved confounding variables. To account for such potential unobserved variable bias, the present study will employ instrumental variable analyses treating physician splitting status as endogenous. We use an indicator variable for the completion of medical training in the state of Florida as an instrument for splitting. Since medical training is predominantly provided in acute-care hospital settings, physicians who have completed periods of medical training in the state of Florida are more likely (compared with physicians trained outside of Florida, yet in the U.S.) to maintain a clinical practice at an acute care hospital in Florida. Moreover, in-state training is plausibly unrelated to other factors influencing patient selection practices. To the extent that in-state training and risk taking behavior are uncorrelated, in state training will provide an exogenous source of variation in splitting (results are reported in Table 3). 
Even with the use of instrumental variables and county fixed-effects models, our analysis relies on comparisons across groups of physicians, and is unable to address patterns of risk selection within individual physicians. To directly examine variation within individual physicians in the selection of settings on patient risk, we exploit the fact that splitters, by definition, operate in both an ASC and a HOPD, with ASCs varying in their geographical distance from a functioning emergency department (ED). Prior research on Emergency Medical Services has identified associations between increasing time required for transportation to emergency care and worsened patient outcomes in a range of care-sensitive conditions (Carr et. al., 2009). ${ }^{13}$ Increasing distance from an emergency department implies an increasing level of procedural risk due to additional time required for transport to care, and, consequently, an increased potential for delays in required care in the event of a complication.

We begin with the choice of setting (ASC vs. HOPD) within individual splitter physicians. Note that the sample includes procedures performed in both ASCs and HOPDs, but is restricted only to physicians who operate in both settings (i.e. splitters). The following model is estimated:

(5) $\quad Y_{i, j, t}=\beta_{A} \cdot A S C_{j, t}+\theta \cdot X_{i, j, t}+\gamma \cdot M_{i}+\phi_{t}+\psi_{j}+\varepsilon_{i, j, t}$, where

the coefficient, $\beta_{A}$, on the setting variable, $A S C_{j, t}$, captures the extent to which treating a patient in an ASC is associated with lower (or higher) surgical risk for a given physician. $\psi_{\mathrm{j}}$ are physician fixed-effects. All other variables are described following our initial regression model in (4)(results are reported in the upper panel of Table 4).

In addition, we examine patterns of risk selection within splitters as a function of facility-to-ED distance. This analysis sheds light on the nature of the tradeoff made by splitters, who are in a better position to choose the site of care (ASC or HOPD) that is the best match to their patients' risk profile. We use the following model:

13 Rapid access to emergency care represents a core element of safe outpatient procedural care as severe complications of ambulatory surgery may lead to emergencies such as myocardial infarction, congestive heart failure, acute respiratory failure. 
where instead of a dichotomous variable for setting of care, $D_{j, t}$ is the distance, in miles, between each ASC and the nearest functioning emergency department as identified through the American Hospital Association Survey and Florida ACHA records. The coefficient, $\beta_{D}$, on the distance variable, captures the extent to which treating a patient further away from an emergency department is associated with lower (or higher) surgical risk for a given physician. $\psi_{\mathrm{j}}$ are physician fixed-effects, developed as dummy variables corresponding to each physician's medical license number, to control for variation in risk selection within physicians (results are reported in the lower panel of Table 4).

Finally, we are interested in the case-level risk for non-splitters and splitters as the distance between the ASC and the nearest acute-care hospital increases. Similar to (4) the analysis considers only procedures performed in ASCs by both splitters and non-splitters. We use the following model:

$$
Y_{i, j, k, t}=\beta_{S} \cdot S_{j, k}+\beta_{D} \cdot D_{j, t}+\alpha \cdot\left(S_{j, k} \cdot D_{j, t}\right)+\theta \cdot X_{i, j, k, t}+\gamma \cdot P_{i}+\delta \cdot M_{j}+\phi_{t}+\mu_{k}+\varepsilon_{i, j, k, t},
$$

where the coefficient, $\alpha$, on the interaction of splitters and distance captures the extent to which splitters select patients with lower (or higher) surgical risk at an ASC as the distance of that ASC from acute-care hospital increases (results are reported in Table 5).

\section{Results}

Tables 2 through 7 report results from estimating equations [4] through [7]. For robustness, each table includes six sample definitions and five regression models for each one of these samples in Tables 2 through 7 . We use two alternative definitions of procedures: the right hand side of each table considers outpatient gastrointestinal endoscopy procedures, the left hand side of each table considers only screening colonoscopies for colon cancer, a set of procedures with uniform indications and constant risk attributable to non-patient factors. Beyond the full sample of patients (upper panel) we stratify the sample to patients below age 65 (middle panel) and patients 65 and above (lower panel), as patients in these 
age brackets have markedly different risk profiles as well as different insurance coverage. For each one of the resulting six samples, we run models with varying degrees of saturation, column [1] and [6] report results from a baseline model with no controls, columns [2] and [7] report results from a model with the full set of controls described above (excluding age), columns [3] and [8] include patient age, , columns [4] and [9] include county fixed effects for the splitter vs. non-splitter specifications and physician fixed effects for the ASC Vs. HOPD specifications (excluding age), columns [5] and [10] repeat the fixed effects analysis with age included in the regression.

\subsection{Splitter versus non-splitter analysis}

Table 2 presents results from estimating eq. (4) regressing the Charlson Comorbidity Index scores on physician splitting status and other controls. Among all UE and colonoscopy patients all models show splitters to perform outpatient procedures on patients with lower Charlson Index score compared with non-splitters. In the fully saturated model, we found patients receiving care from non-splitters to have a 0.0168 points higher Charlson Index score (42\% higher). Similar results were obtained in samples stratified by age (below age 65 versus age 65 and over), with the largest magnitude of difference in patient risk being in patients over 65 , where Charlson scores were $44.9 \%$ higher for patients receiving care from non-splitters. Identical specifications restricted to screening colonoscopy for colon cancer produced results similar in direction but about four times greater in magnitude, with the fully-saturated models estimating case risk among nonsplitters to be $182.5 \%$ (full sample) and $168.2 \%$ (age 65 and over) higher in Charlson score. ${ }^{14}$

As the distribution of the Charlson score exhibits statistically significant overdispersion $(\alpha=8.3)$, Table 3 reports results from estimating eq. (4) using a negative binomial regression model with a quadratic variance function, which is considered to be a flexible functional form for overdispersed count data. The results for the full samples (columns [1] through [5]) are similar in magnitude to those presented in Table 2. The results for the screening colonoscopy samples (columns [6] through [10]) are roughly three times smaller in magnitude compared with those obtained using OLS. This is not surprising, as the proportion of low risk patients (i.e. Charlson score of zero) is far greater for screening colonoscopies. Similar results were

\footnotetext{
${ }^{14}$ To explore the possibility of nonrandom assignment of splitters and non-splitters to patients, we regress the patient gender and race on the splitter status dummy. The results suggest that splitter status is unrelated to most patient characteristics across all models. In the few instances in which splitter status has some statistical significance, the magnitudes of the coefficients are extremely small.
} 
obtained from estimating zero inflated negative binomial models, in which the model allows the mechanism generating the zero observations to differ from the one for the positive observations (results not reported).

As a further robustness check, we condensed the sample using Rosenbaum and Rubin's (1983) propensity score matching approach. Patients with high surgical risk were matched to those with low surgical risk (i.e. Charlson score of zero) on age, gender, race, year-quarter of procedure, and insurance type using a one-to-one nearest neighbor matching without replacement, along all these observable, patient-level, dimensions. ${ }^{15}$ Table 4 presents results from estimating eq. (4) using OLS and negative binomial regression models on the matched samples. The results are consistent with those reported in tables 2 and 3. By construction, patients with elevated surgical risk are over represented in this sample, which explains the larger magnitude of the coefficient estimates reported in Table 4.

Instrumental variable analyses (Table 5) show a similar direction of effect, with the coefficient on the predicted splitter variable appearing negative and significant in all regressions. The instrument (completion of medical school in Florida) was strongly predictive of splitting status in the first stage across all specifications, suggesting between $4 \%$ and $7.5 \%$ increase in the likelihood of splitting when attending medical school in Florida. ${ }^{16}$

\subsection{ASC versus HOPD analysis}

Expanding our analytic sample to all facilities (ASCs and HOPDs) while limiting it to splitters, the upper panel of Table 6 presents results estimating eq. (5) above. Among EGD and colonoscopy patients, we found splitters to consistently provide care to lower-risk patients in ASCs, results which were robust to all above controls, as well as physician fixed-effects, in samples including all patients as well as those restricted to patients aged 65 and over. Differences in risk profiles between ASC and HOPD patients were most pronounced in patients aged 65 or older, with the fully-saturated models predicting

\footnotetext{
15 Results are robust to a more conventional approach of matching on splitter status. However, under such a strategy, the overdispersion problem persists, as both splitters and non-splitters treat mostly low risk patients and less than $1 \%$ of patients do not fall on the common support of the estimated propensity score distribution.

${ }^{16}$ Standard diagnostics indicate that attending medical school in Florida is a strong instrument in terms of its partial correlation with the splitter variable. Even for the more restricted colonoscopy-only sample, the partial $R^{2}$ for the first stage regression is 0.0055 with cluster robust F-statistic (1.934) of 138.52 compared with the customary weak-instrument benchmark of 10.
} 
HOPD patient complexity to be $244.6 \%$ higher among EGD and colonoscopy patients and $279.6 \%$ higher among screening colonoscopy-only patients.

The lower panel of Table 6 follows eq. (6) and reports results regarding the effect of distance on selection behaviors. While similar in direction and significance, these effects were smaller in magnitude than differences observed across facility types, and remained consistent across all regression models. As in the comparisons of risk across settings, these findings were most pronounced in the fully-saturated, physician fixed-effects models for patients aged 65 or older, where an additional mile further away from the nearest acute care hospital was associated with a $55.6 \%$ (UE and colonoscopy), and $74.1 \%$ (screening colonoscopy only) reduction in the average ASC patient's medical complexity.

\subsection{Within ASCs analysis revisited: the effect of distance from ED}

Table 7 reports results from comparisons of splitters and non-splitters within ASCs to examine the difference in the effect of changing distance on risk selection according to the physician's division of labor (as described in eq. (7)). Our findings indicate a consistently negative and significant effect of splitting status on average patient risk profile, and a consistently negative and significant effect of distance on average patient risk profiles within ASCs among non-splitters. In all models, the interaction of splitting status and distance was significant and positive, consistent with model predictions that differences in patient selection between splitters and non-splitters shrink with increasing distance from an acute-care hospital. As above, the estimated magnitude of this effect varies with the subset of procedures under study and the age stratum sampled; nonetheless, our findings predict that the distances at which distance effects would negate the effects of splitting fall within the range of distances of ASCs in Florida from acute care hospitals: 3.38-3.9 miles (all outpatient gastrointestinal endoscopies) and 1.54-1.97 miles (screening colonoscopy only).

\section{$\underline{\text { 6. Conclusions }}$}

Our findings indicate that patients with higher medical complexity are more likely to receive treatment in HOPDs (as opposed to ASCs). Further, we find that patient selection for ASC care is potentially sensitive to differences in the opportunity cost of HOPD referral, as identified by variations in physician division-of-labor, patient medical complexity, and 
ASC location. Within ASCs, those physicians who work exclusively in ASCs tend to take on more risk compared to their splitter counterparts. This behavior weakens as (1) the ASC is located further away from emergency capabilities, (2) patients are over 65, and (3) procedures are more risky. The effects we observe persist despite adjustment for patient characteristics, secular time, physician characteristics, county fixed effects, and when using an instrument for splitting status to mitigate concerns regarding omitted variable bias. Further, these effects persist in samples defined through a variety of procedure and patient-based exclusion criteria, and are robust to a range of alternate definitions of key variables. In all these cases, we identify a group of patients with a level of surgical risk that would prompt treatment at an HOPD by a splitter, while a non-splitter would treat these patients at an ASC.

ASCs are often portrayed as engaging in "cream skimming" of low risk patients, with the potential to decrease welfare by limiting the ability of acute care hospitals to cross-subsidize the costs of unprofitable services (Lynk \& Longley, 2002). While we find high risk patients to be more likely to receive treatment in settings with increased backup capabilities (i.e. HOPDs), the degree of such selection practices may depend on the ability of an individual physician to benefit from a referral. Professional standards and scrutiny by regulators create legal and ethical opposition to kickbacks, preventing fee-splitting between physicians for referrals. While such structures are intended to prevent fraudulent over-use of services, our work illustrates a case where such prohibitions may be adverse to welfare by potentially hindering medically justified referrals from ASC-only physicians to those with access to HOPDs. Similarly, our work suggests that such prohibitions against feesplitting have the potential to lead to an inefficient number of splitters, if individuals who otherwise would have specialized in the delivery of care only in ASCs maintain practices at HOPDs due to the cost of out-referral.

Mismatches between patient complexity and facility capabilities have the potential to result in patient harm and excess costs of care. We find decision making regarding the setting of otherwise identical outpatient procedures to be sensitive to differences in the opportunity cost of sending a patient to an HOPD versus an ASC, such that selection practices by nonsplitters may be more likely to create such mismatches. 
Arrow, Kenneth J. "Uncertainty and the Welfare Economics of Medical Care." The American Economic Review. Vol. 53. No. 5 (1963): 941-973.

Bian, John, and Michael A. Morrisey. "Free-Standing Ambulatory Surgery Centers and Hospital Surgery Volume." Inquiry. Vol. 44. No. 2 (2007): 200-210.

Blomqvist, ^̊ and Léger, PT. 2005. Information asymmetry, insurance, and the decision to hospitalize. Journal of Health Economics 24:775-793.

Bryson GL, Chung F, Finegan BA, et al. Patient selection in ambulatory anesthesia - an evidence-based review: part I. Can J Anaesth. Oct 2004;51(8):768-781.

Carr BG, Branas CC, Metlay JP, Sullivan AF, Camargo CA, Jr. 2009. Access to emergency care in the United States. Annals of Emergency Medicine; 54(2):261-9.

Casalino LP, Devers KJ, Brewster LR. Focused factories? Physician-owned specialty facilities. Health Aff (Millwood). 2003;22(6):56-67.

Charlson ME, Pompei P, Ales KL, MacKenzie CR. A new method of classifying prognostic comorbidity in longitudinal studies: development and validation. J Chronic Dis. 1987;40(5):373-383.

Cullen, K.A., Hall, M.J., \& Golosinskiy, A. Ambulatory surgery in the United States, 2006. National Health Statistics Report (11), 1-25.

David, Guy and Lorens Helmchen. The Role of Task Adhesion in Limiting Specialization along the Medical Care Continuum. Review of Labour Economics and Industrial Relations, 2010. 24(2).

Evans, R., 1974. Supplier-induced demand: some empirical evidence and implications, In: M. Perlman, Editor. The Economics of Health and Medical Care (Macmillan, London) 162-173.

Fleisher LA, Pasternak LR, Herbert R, Anderson GF. Inpatient hospital admission and death after outpatient surgery in elderly patients: importance of patient and system characteristics and location of care. Arch Surg. Jan 2004; 139(1):67-72.

Gruber, Jonathan, and Maria Owings. "Physician Financial Incentives and Cesarean Section Delivery." The RAND Journal of Economics. Vol. 27. No. 1 (1996): 99-123.

Labelle, Robera, Greg Stoddart, and Thomas Rice. "A Re-Examination of the Meaning and Importance of Supplier-Induced Demand". Journal of Health Economics. Vol. 13. 1994: 347-368. 
Lynk, William J., and Carina S. Longley. "The Effect of Physician-Owned Surgicenters on Hospital Outpatient Surgery." Health Affairs. Vol. 21. No. 4 (2002): 215-221.

Marinoso, B.G. and Jelovac, I., 2003. GPs payment contracts and their referral practice. Journal of Health Economics 22, 617-635.

McGuire, Thomas G., 2000. Chapter 9 Physician agency, In: Anthony J. Culyer and Joseph P. Newhouse, Editor(s), $\underline{\text { Handbook }}$ of Health Economics, Elsevier, Volume 1, Part 1, Pages 461-536.

McGuire, Thomas G., and Mark V. Pauly. "Physician Response to Fee Changes with Multiple Payers." Journal of Health Economics. Vol. 10. 1991: 385-410.

MedPAC. 2004. Medicare Payment Advisory Commission Report to Congress: Medicare Payment Policy. Washington, DC: MedPAC.

Medicare Payment Advisory Commission (2009). Ambulatory Care. In: A Data Book: Health Care Spending and the Medicare Program (pp 97-120). Washington, D.C.

Rosenbaum, P.R., D.B. Rubin. 1983. The central role of the propensity score in observational studies for causal effects. Biometrika 70(1) 41-55.

Quan H, Sundararajan V, Halfon P, et al. Coding algorithms for defining comorbidities in ICD-9-CM and ICD-10 administrative data. Med Care. Nov 2005;43(11):1130-1139. 
Figure 1: Surgeon's utility as a function of surgical risk and splitter status

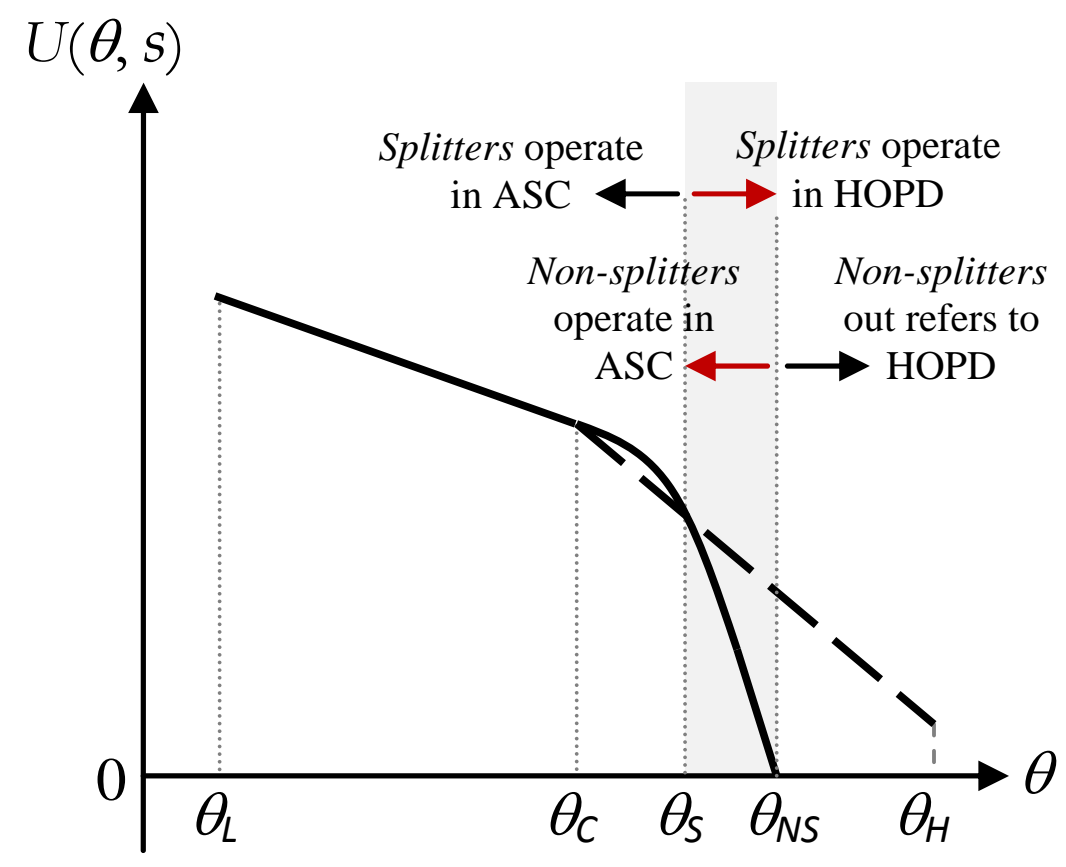


Figure 2: Average Charlson score by procedure, age group, care setting, and splitter status: Florida, 2004-2007
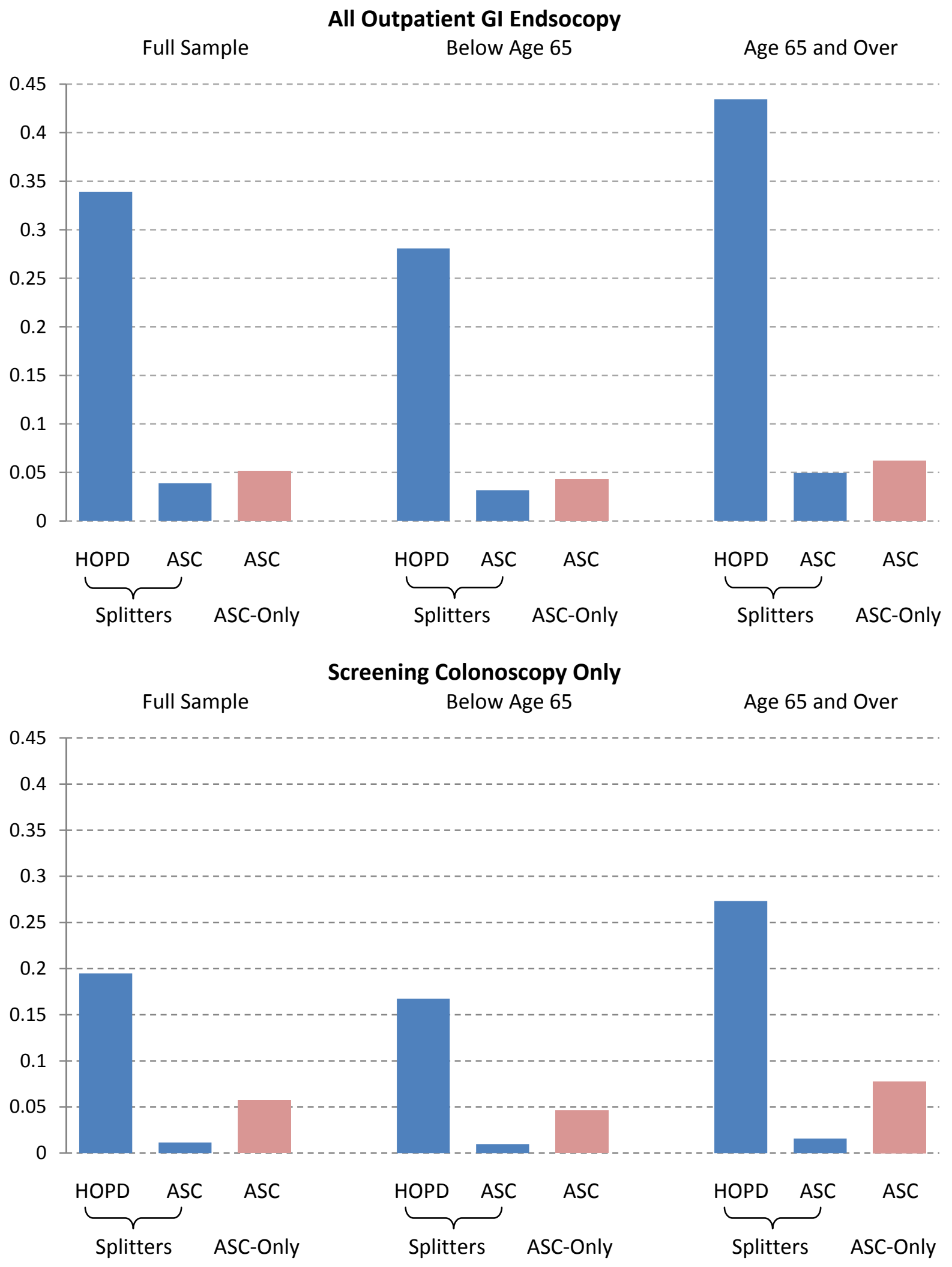
Table 1: Summary Statistics

\begin{tabular}{|c|c|c|c|c|}
\hline & \multicolumn{2}{|c|}{ Full Sample } & \multicolumn{2}{|c|}{ Colonoscopy-Only Sample } \\
\hline & Splitters & Non-Splitters & Splitters & Non-Splitters \\
\hline Average Share of Cases at ASC & $\begin{array}{c}0.68 \\
(0.27)\end{array}$ & $\begin{array}{c}0.995 \\
(0.007)\end{array}$ & $\begin{array}{c}0.62 \\
(0.32)\end{array}$ & $\begin{array}{c}0.995 \\
(0.007)\end{array}$ \\
\hline Charlson Score (ASC Patients) & $\begin{array}{l}0.039 \\
(0.26)\end{array}$ & $\begin{array}{c}0.0513 \\
(0.29)\end{array}$ & $\begin{array}{c}0.0116 \\
(0.13)\end{array}$ & $\begin{array}{c}0.0572 \\
(0.29)\end{array}$ \\
\hline Charlson Score (HOPD Patients) & $\begin{array}{c}0.3389 \\
(0.80)\end{array}$ & N/A & $\begin{array}{c}0.1948 \\
(0.51)\end{array}$ & N/A \\
\hline Age (Mean) & $\begin{array}{c}60.07 \\
(14.32)\end{array}$ & $\begin{array}{c}62.07 \\
(14.18)\end{array}$ & $\begin{array}{l}60.28 \\
(8.56)\end{array}$ & $\begin{array}{c}61.5 \\
(9.19)\end{array}$ \\
\hline Male (\%) & 43.27 & 43.8 & 45.36 & 48.08 \\
\hline Share of Upper Endoscopy (\%) & 29.87 & 33.16 & & \\
\hline Additional Procedure (\%) & 35.65 & 25.69 & 23.38 & 10.1 \\
\hline \multicolumn{5}{|l|}{ Race (\%) } \\
\hline White & 76.12 & 73.27 & 72.09 & 64.48 \\
\hline Black & 8.27 & 7.04 & 10.6 & 13.75 \\
\hline Hispanic & 11.04 & 16.14 & 11.48 & 16.03 \\
\hline Other Race & 4.56 & 3.55 & 5.84 & 5.74 \\
\hline \multicolumn{5}{|l|}{ Payer (\%) } \\
\hline Medicare & 36.71 & 41.19 & 23.92 & 21.93 \\
\hline Medicaid & 2.02 & 2.37 & 1.2 & 0.83 \\
\hline Private Insurance & 56.67 & 53.72 & 69.7 & 75.58 \\
\hline Self-Pay/Charity & 1.67 & 1.34 & 1.84 & 0.7 \\
\hline Other & 2.92 & 1.38 & 3.31 & 0.95 \\
\hline Mean Phys. Years in Practice & $\begin{array}{l}24.11 \\
(7.83)\end{array}$ & $\begin{array}{l}28.28 \\
(7.56)\end{array}$ & $\begin{array}{l}24.63 \\
(8.09)\end{array}$ & $\begin{array}{l}29.45 \\
(6.92)\end{array}$ \\
\hline Forign Medical Trainee Physician (\%) & 35.47 & 43.58 & 34.18 & 27.65 \\
\hline Gastroenterology Subspecialist (\%) & 87.97 & 87.52 & 86.74 & 86.31 \\
\hline Florida Trainee (\%) & 12.65 & 5.83 & 12.58 & 2.86 \\
\hline
\end{tabular}


Table 2: The effect of splitter status on surgical risk selection in Florida ASCs, 2004-2007 (Linear regression models)

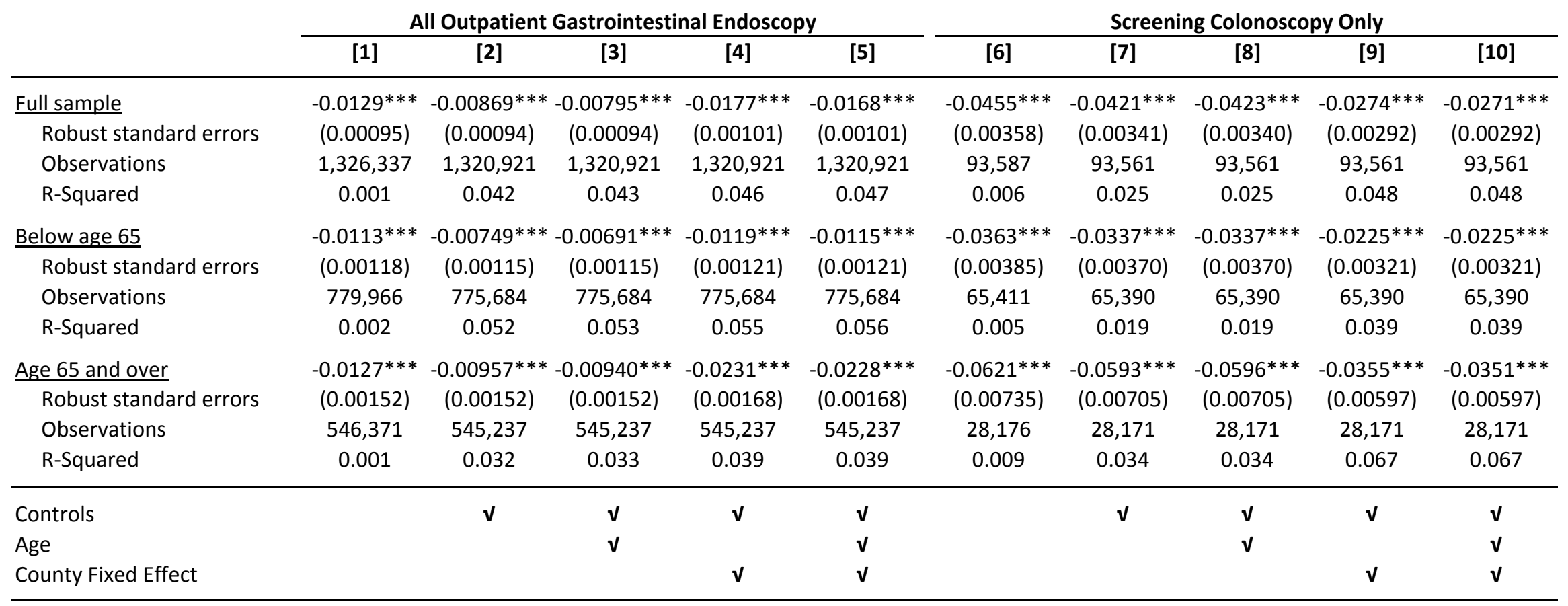

Notes: Heteroskedasticity-robust standard errors are reported in brackets below the estimated coefficients. "*", "**", and "***" indicate significance at the $10 \%, 5 \%$, and $1 \%$ levels, respectively. Controls include year and quarter dummies, patient race, patient gender, 23 procedure categories, 12 insurance type categories, physician experience (years since graduation), an indicator for fellowship-level training in gastroenterology, and foreign medical graduate status (U.S.-based versus foreign). 
Table 3: The effect of splitter status on surgical risk selection in Florida ASCs, 2004-2007 (Negative Binomial regression models)

\begin{tabular}{|c|c|c|c|c|c|c|c|c|c|c|}
\hline & \multicolumn{5}{|c|}{ All Outpatient Gastrointestinal Endoscopy } & \multicolumn{5}{|c|}{ Screening Colonoscopy Only } \\
\hline & [1] & [2] & [3] & [4] & [5] & [6] & [7] & [8] & [9] & [10] \\
\hline Full sample & $-0.0105^{* * *}$ & $-0.00902 * * *$ & $-0.0094 * * *$ & $-0.0098 * * *$ & $-0.0097 * * *$ & $-0.0192 * * *$ & $-0.01493^{* * *}$ & $-0.0167 * * *$ & $-0.0065^{* * *}$ & $-0.0063 * * *$ \\
\hline Robust standard errors & $(0.00073)$ & $(0.00075)$ & (0.00069) & $(0.00081)$ & $(0.00081)$ & $(0.00103)$ & (0.00089) & $(0.00083)$ & $(0.00093)$ & $(0.00093)$ \\
\hline Observations & $1,320,921$ & $1,320,921$ & $1,320,921$ & $1,320,921$ & $1,326,337$ & 93,587 & 93,561 & 93,561 & 93,561 & 93,561 \\
\hline Pseudo R2 & 0.0005 & 0.0609 & 0.0052 & 0.0119 & 0.0162 & 0.0249 & 0.1126 & 0.0302 & 0.1036 & 0.1075 \\
\hline Below age 65 & $-0.0092^{* * *}$ & $-0.00869 * * *$ & $-0.0088^{* * *}$ & $-0.0085^{* * *}$ & $-0.0086 * * *$ & $-0.0157^{* * *}$ & $-0.01322^{* * *}$ & $-0.0141 * * *$ & $-0.0062 * * *$ & $-0.0061 * * *$ \\
\hline Robust standard errors & (0.00089) & $(0.00093)$ & $(0.00086)$ & $(0.00096)$ & $(0.00096)$ & $(0.00114)$ & $(0.00103)$ & $(0.00094)$ & (0.00104) & $(0.00104)$ \\
\hline Observations & 775,684 & 775,684 & 775,684 & 775,684 & 775,684 & 65,411 & 65,390 & 65,390 & 65,390 & 65,390 \\
\hline Pseudo R2 & 0.0005 & 0.0671 & 0.0015 & 0.0110 & 0.0118 & 0.0219 & 0.1053 & 0.0229 & 0.0968 & 0.0976 \\
\hline Age 65 and over & $-0.0105^{* * *}$ & $-0.00948^{* * *}$ & $-0.0102 * * *$ & $-0.0102 * * *$ & $-0.0101 * * *$ & $-0.0263 * * *$ & $-0.01856^{* * *}$ & $-0.0229 * * *$ & $-0.0069 * * *$ & $-0.0068 * * *$ \\
\hline Robust standard errors & $(0.00122)$ & $(0.00123)$ & $(0.00117)$ & $(0.00142)$ & $(0.00142)$ & $(0.00216)$ & $(0.00177)$ & $(0.00170)$ & (0.00197) & $(0.00196)$ \\
\hline Observations & 545,237 & 545,237 & 545,237 & 545,237 & 545,237 & 28,176 & 28,171 & 28,171 & 28,171 & 28,171 \\
\hline Pseudo R2 & 0.0004 & 0.0514 & 0.0023 & 0.0136 & 0.0155 & 0.0279 & 0.1259 & 0.0301 & 0.1205 & 0.1223 \\
\hline Controls & & $\boldsymbol{v}$ & $\mathbf{v}$ & $\mathbf{v}$ & $\mathbf{v}$ & & $\mathbf{v}$ & $\mathbf{v}$ & $\mathbf{v}$ & $\mathbf{v}$ \\
\hline Age & & & v & & $\mathbf{v}$ & & & $\mathbf{v}$ & & v \\
\hline County Fixed Effect & & & & $\mathbf{v}$ & $\mathbf{v}$ & & & & $\mathbf{v}$ & $\mathbf{v}$ \\
\hline
\end{tabular}

Notes: Heteroskedasticity-robust standard errors are reported in brackets below the estimated coefficients. "*", "**", and "***" indicate significance at the $10 \%, 5 \%$, and $1 \%$ levels, respectively. Controls include year and quarter dummies, patient race, patient gender, 23 procedure categories, 12 insurance type categories, physician experience (years since graduation), an indicator for fellowship-level training in gastroenterology, and foreign medical graduate status (U.S.-based versus foreign). 
Table 4: The effect of splitter status on surgical risk selection in Florida ASCs, 2004-2007 (matched samples)

All Outpatient Gastrointestinal Endoscopy

\begin{tabular}{|c|c|c|c|c|c|c|c|c|c|c|}
\hline & \multicolumn{5}{|c|}{ All Uutpatient Gastrointestinal Enaoscopy } & \multicolumn{5}{|c|}{ screening Colonoscopy Uniy } \\
\hline & [1] & [2] & [3] & [4] & [5] & [6] & [7] & [8] & [9] & [10] \\
\hline Full sample & $-0.1246 * * *$ & $-0.1184 * * *$ & $-0.1057 * * *$ & $-0.0997 * * *$ & $-0.0716 * * *$ & $-0.4118 * * *$ & $-0.4309 * * *$ & $-0.2779 * * *$ & $-0.2923 * * *$ & $-0.1432 * * *$ \\
\hline Robust standard errors & $(0.01110)$ & $(0.00275)$ & $(0.00878)$ & $(0.00877)$ & $(0.01237)$ & $(0.04082)$ & $(0.04127)$ & $(0.02260)$ & $(0.02286)$ & $(0.05168)$ \\
\hline Observations & 77,532 & 77,532 & 77,532 & 77,532 & 77,532 & 2,288 & 2,288 & 2,288 & 2,288 & 2,288 \\
\hline R-Sq [Pseudo R-Sq] & 0.0017 & 0.0063 & {$[0.0007]$} & {$[0.0028]$} & 0.1571 & 0.0462 & 0.0558 & [0.0181] & {$[0.0224]$} & 0.1723 \\
\hline Below age 65 & $-0.0859 * * *$ & $-0.0746 * * *$ & $-0.0745^{* * *}$ & $-0.0640 * * *$ & $-0.0771 * * *$ & $-0.3564 * * *$ & $-0.3816 * * *$ & $-0.2518 * * *$ & $-0.2658 * * *$ & $-0.1129 * * *$ \\
\hline Robust standard errors & $(0.01640)$ & $(0.01636)$ & $(0.01355)$ & $(0.01344)$ & $(0.01778)$ & $(0.05081)$ & (0.05193) & $(0.02934)$ & $(0.02985)$ & $(0.06276)$ \\
\hline Observations & 37,228 & 37,228 & 37,228 & 37,228 & 37,228 & 1,348 & 1,348 & 1,348 & 1,348 & 1,348 \\
\hline R-Sq [Pseudo R-Sq] & 0.0007 & 0.0099 & [0.0013] & {$[0.0046]$} & 0.143 & 0.0364 & 0.0551 & [0.0143] & [0.0241] & 0.208 \\
\hline Age 65 and over & $-0.1615^{* * *}$ & $-0.1605^{* * *}$ & $-0.1342 * * *$ & $-0.1330 * * *$ & $-0.0628 * * *$ & $-0.4637 * * *$ & $-0.4957 * * *$ & $-0.3042 * * *$ & $-0.3273 * * *$ & $-0.1215^{* * *}$ \\
\hline Robust standard errors & $(0.01508)$ & $(0.01512)$ & $(0.01147)$ & $(0.01150)$ & $(0.01718)$ & $(0.06625)$ & $(0.06715)$ & $(0.03525)$ & $(0.03571)$ & $(0.08980)$ \\
\hline Observations & 40,304 & 40,304 & 40,304 & 40,304 & 40,304 & 940 & 940 & 940 & 940 & 940 \\
\hline R-Sq [Pseudo R-Sq] & 0.0029 & 0.0055 & {$[0.0003]$} & {$[0.0025]$} & 0.1867 & 0.0557 & 0.0675 & {$[0.0230]$} & {$[0.0286]$} & 0.1629 \\
\hline Controls & & $\mathbf{v}$ & & $\mathbf{V}$ & $\sqrt{ }$ & & $\sqrt{ }$ & & $\mathbf{v}$ & $\sqrt{ }$ \\
\hline Neg. Binomial (marginal eff & cts) & & $\sqrt{ }$ & $\boldsymbol{V}$ & & & & $\sqrt{ }$ & $\sqrt{ }$ & \\
\hline County Fixed Effect & & & & & $\sqrt{ }$ & & & & & $\sqrt{ }$ \\
\hline
\end{tabular}

Notes: Heteroskedasticity-robust standard errors are reported in brackets below the estimated coefficients. "*", "**", and "***" indicate significance at the $10 \%, 5 \%$, and $1 \%$ levels, respectively. Controls include year and quarter dummies, patient race, patient gender, 23 procedure categories, 12 insurance type categories, physician experience (years since graduation), an indicator for fellowship-level training in gastroenterology, and foreign medical graduate status (U.S.-based versus foreign). 
Table 5: The effect of splitter status on surgical risk selection in Florida ASCs, 2004-2007 (using medical training in Florida as an instrument)

\begin{tabular}{|c|c|c|c|c|c|c|c|c|c|c|}
\hline & \multicolumn{5}{|c|}{ All Outpatient Gastrointestinal Endoscopy } & \multicolumn{5}{|c|}{ Screening Colonoscopy Only } \\
\hline & [1] & [2] & [3] & [4] & [5] & [6] & [7] & [8] & [9] & [10] \\
\hline \multicolumn{11}{|l|}{ Full sample } \\
\hline Splitter & $\begin{array}{c}-0.238 * * * \\
(0.0126)\end{array}$ & $\begin{array}{c}-0.140 * * * \\
(0.0134)\end{array}$ & $\begin{array}{c}-0.137^{* * *} \\
(0.0135)\end{array}$ & $\begin{array}{c}-0.208 * * * \\
(0.0142)\end{array}$ & $\begin{array}{c}-0.198 * * * \\
(0.0143)\end{array}$ & $\begin{array}{c}-0.142 * * * \\
(0.0182)\end{array}$ & $\begin{array}{c}-0.0883 * * * \\
(0.0199)\end{array}$ & $\begin{array}{c}-0.0877^{* * *} \\
(0.0201)\end{array}$ & $\begin{array}{c}-0.124 * * * \\
(0.0208)\end{array}$ & $\begin{array}{c}-0.123 * * * \\
(0.0211)\end{array}$ \\
\hline IV (first stage) & $\begin{array}{c}0.0501 * * * \\
(0.0005)\end{array}$ & $\begin{array}{c}0.0453^{* * *} \\
(0.0005)\end{array}$ & $\begin{array}{c}0.0452 * * * \\
(0.0005)\end{array}$ & $\begin{array}{c}0.0463 * * * \\
(0.0004)\end{array}$ & $\begin{array}{c}0.0460 * * * \\
(0.0004)\end{array}$ & $\begin{array}{c}0.0627^{* * *} \\
(0.0015)\end{array}$ & $\begin{array}{c}0.0556 * * * \\
(0.0016)\end{array}$ & $\begin{array}{c}0.0551 * * * \\
(0.0016)\end{array}$ & $\begin{array}{c}0.0602 * * * \\
(0.0016)\end{array}$ & $\begin{array}{c}0.0592 * * * \\
(0.0016)\end{array}$ \\
\hline Observations & $1,326,337$ & $1,320,921$ & $1,320,921$ & $1,320,921$ & $1,320,921$ & 93,587 & 93,561 & 93,561 & 93,561 & 93,561 \\
\hline R-Squared & 0.001 & 0.024 & 0.026 & 0.017 & 0.020 & 0.001 & 0.018 & 0.018 & 0.023 & 0.024 \\
\hline \multicolumn{11}{|l|}{ Below age 65} \\
\hline Splitter & $\begin{array}{c}-0.239 * * * \\
(0.0132)\end{array}$ & $\begin{array}{c}-0.156 * * * \\
(0.0139)\end{array}$ & $\begin{array}{c}-0.154 * * * \\
(0.0139)\end{array}$ & $\begin{array}{c}-0.193 * * * \\
(0.0146)\end{array}$ & $\begin{array}{c}-0.189 * * * \\
(0.0146)\end{array}$ & $\begin{array}{c}-0.129 * * * \\
(0.0209)\end{array}$ & $\begin{array}{c}-0.0907^{* * *} \\
(0.0221)\end{array}$ & $\begin{array}{c}-0.0905^{* * *} \\
(0.0222)\end{array}$ & $\begin{array}{c}-0.113^{* * *} \\
(0.0232)\end{array}$ & $\begin{array}{c}-0.113 * * * \\
(0.0232)\end{array}$ \\
\hline IV (first stage) & $\begin{array}{c}0.0523 * * * \\
(0.0006)\end{array}$ & $\begin{array}{c}0.0473 * * * \\
(0.0006)\end{array}$ & $\begin{array}{c}0.0473 * * * \\
(0.0006)\end{array}$ & $\begin{array}{c}0.0486 * * * \\
(0.0005)\end{array}$ & $\begin{array}{c}0.0486 * * * \\
(0.0005)\end{array}$ & $\begin{array}{c}0.0575 * * * \\
(0.0018)\end{array}$ & $\begin{array}{c}0.0524 * * * \\
(0.0018)\end{array}$ & $\begin{array}{c}0.0524^{* * *} \\
(0.0018)\end{array}$ & $\begin{array}{c}0.0561 * * * \\
(0.0018)\end{array}$ & $\begin{array}{c}0.0560 * * * \\
(0.0018)\end{array}$ \\
\hline Observations & 779,966 & 775,684 & 775,684 & 775,684 & 775,684 & 65,411 & 65,390 & 65,390 & 65,390 & 65,390 \\
\hline R-Squared & 0.002 & 0.027 & 0.029 & 0.025 & 0.027 & 0.002 & 0.008 & 0.008 & 0.013 & 0.013 \\
\hline \multicolumn{11}{|l|}{ Age 65 and over } \\
\hline Splitter & $\begin{array}{c}-0.208 * * * \\
(0.0268)\end{array}$ & $\begin{array}{c}-0.113^{* * *} \\
(0.0284)\end{array}$ & $\begin{array}{c}-0.110 * * * \\
(0.0284)\end{array}$ & $\begin{array}{c}-0.237^{* * *} \\
(0.0314)\end{array}$ & $\begin{array}{c}-0.233^{* * *} \\
(0.0314)\end{array}$ & $\begin{array}{c}-0.152 * * * \\
(0.0365)\end{array}$ & $\begin{array}{c}-0.0885^{* *} \\
(0.0448)\end{array}$ & $\begin{array}{l}-0.0874 * \\
(0.0449)\end{array}$ & $\begin{array}{c}-0.187^{* * *} \\
(0.0519)\end{array}$ & $\begin{array}{c}-0.185 * * * \\
(0.0521)\end{array}$ \\
\hline IV (first stage) & $\begin{array}{c}0.0452 * * * \\
(0.0010)\end{array}$ & $\begin{array}{c}0.0414^{* * *} \\
(0.0010)\end{array}$ & $\begin{array}{c}0.0413^{* * *} \\
(0.0010)\end{array}$ & $\begin{array}{c}0.0411^{* * *} \\
(0.0008)\end{array}$ & $\begin{array}{c}0.0410 * * * \\
(0.0008)\end{array}$ & $\begin{array}{c}0.0748 * * * \\
(0.0029)\end{array}$ & $\begin{array}{c}0.0607 * * * \\
(0.0029)\end{array}$ & $\begin{array}{c}0.0604 * * * \\
(0.0030)\end{array}$ & $\begin{array}{c}0.0613 * * * \\
(0.0036)\end{array}$ & $\begin{array}{c}0.0609 * * * \\
(0.0036)\end{array}$ \\
\hline Observations & 546,371 & 545,237 & 545,237 & 545,237 & 545,237 & 28,176 & 28,171 & 28,171 & 28,171 & 28,171 \\
\hline R-Squared & 0.001 & 0.023 & 0.023 & 0.006 & 0.008 & 0.002 & 0.032 & 0.032 & 0.023 & 0.024 \\
\hline Controls & & v & v & $\mathbf{v}$ & $\mathbf{v}$ & & $\sqrt{ }$ & $\mathbf{v}$ & $\mathbf{v}$ & $\mathbf{v}$ \\
\hline Age & & & $\mathbf{v}$ & & $\mathbf{v}$ & & & $\mathbf{v}$ & & $\sqrt{ }$ \\
\hline County Fixed Effect & & & & $\boldsymbol{v}$ & $\boldsymbol{V}$ & & & & $\sqrt{ }$ & $\mathbf{v}$ \\
\hline
\end{tabular}

Notes: Heteroskedasticity-robust standard errors are reported in brackets below the estimated coefficients. "*", "**", and "***" indicate significance at the $10 \%, 5 \%$, and $1 \%$ levels, respectively. Controls include year and quarter dummies, patient race, patient gender, 23 procedure categories, 12 insurance type categories, physician experience (years since graduation), an indicator for fellowship-level training in gastroenterology, and foreign medical graduate status (U.S.-based versus foreign). 
Table 6: The effect of care setting and distance to the nearest acute care hospital on splitter physicians' choice of surgical risk in Florida ASCs

Dependent Variable:

All Outpatient Gastrointestinal Endoscopy

Screening Colonoscopy Only

\begin{tabular}{|c|c|c|c|c|c|c|c|c|c|c|}
\hline \multicolumn{6}{|l|}{ Chalsan Coro } & & & & & \\
\hline Charlson Score & [1] & [2] & [3] & [4] & [5] & [6] & [7] & [8] & [9] & [10] \\
\hline \multicolumn{11}{|l|}{ ASC indicator variable } \\
\hline Full sample & $-0.300 * * *$ & $-0.256 * * *$ & $-0.255^{* * *}$ & $-0.276 * * *$ & $-0.275 * * *$ & $-0.183 * * *$ & $-0.158 * * *$ & $-0.157 * * *$ & $-0.167 * * *$ & $-0.166 * * *$ \\
\hline Robust std. errors & $(0.001200)$ & $(0.001140)$ & $(0.001140)$ & $(0.001370)$ & $(0.001370)$ & $(0.002650)$ & $(0.002790)$ & $(0.002790)$ & $(0.003360)$ & $(0.003360)$ \\
\hline Observations & $1,683,927$ & $1,681,877$ & $1,681,877$ & $1,683,882$ & $1,683,882$ & 124,188 & 123,855 & 123,855 & 124,185 & 124,185 \\
\hline R-Squared & 0.074 & 0.167 & 0.166 & 0.179 & 0.177 & 0.074 & 0.091 & 0.091 & 0.112 & 0.112 \\
\hline Below age 65 & $-0.249 * * *$ & $-0.205 * * *$ & $-0.205^{* * *}$ & $-0.224 * * *$ & $-0.224 * * *$ & $-0.158 * * *$ & $-0.134 * * *$ & $-0.135 * * *$ & $-0.143 * * *$ & $-0.143 * * *$ \\
\hline Robust std. errors & $(0.001430)$ & $(0.001340)$ & $(0.001350)$ & (0.001620) & $(0.001620)$ & $(0.002870)$ & $(0.003030)$ & $(0.003030)$ & $(0.003610)$ & $(0.003610)$ \\
\hline Observations & $1,011,181$ & $1,009,851$ & $1,009,851$ & $1,011,154$ & $1,011,154$ & 88,668 & 88,457 & 88,457 & 88,668 & 88,668 \\
\hline R-Squared & 0.059 & 0.177 & 0.174 & 0.189 & 0.186 & 0.064 & 0.083 & 0.082 & 0.109 & 0.108 \\
\hline Age 65 and over & $-0.385 * * *$ & $-0.335 * * *$ & $-0.335 * * *$ & $-0.367 * * *$ & $-0.367 * * *$ & $-0.258 * * *$ & $-0.223 * * *$ & $-0.223 * * *$ & $-0.240 * * *$ & $-0.240 * * *$ \\
\hline Robust std. errors & $(0.002100)$ & $(0.002020)$ & $(0.002020)$ & $(0.002500)$ & $(0.002500)$ & $(0.006050)$ & $(0.006390)$ & $(0.006390)$ & $(0.008440)$ & $(0.008440)$ \\
\hline Observations & 672,746 & 672,026 & 672,026 & 672,728 & 672,728 & 35,520 & 35,398 & 35,398 & 35,517 & 35,517 \\
\hline R-Squared & 0.1 & 0.166 & 0.166 & 0.18 & 0.18 & 0.106 & 0.116 & 0.116 & 0.151 & 0.151 \\
\hline \multicolumn{11}{|l|}{ Distance (in Miles) } \\
\hline Full sample & $-0.0407 * * *$ & $-0.0292 * * *$ & $-0.0293 * * *$ & $-0.0662 * * *$ & $-0.0662 * * *$ & $-0.0367 * * *$ & $-0.0256 * * *$ & $-0.0256 * * *$ & $-0.0465 * * *$ & $-0.0464 * * *$ \\
\hline Robust std. errors & $(0.000235)$ & $(0.000203)$ & $(0.000202)$ & $(0.000577)$ & $(0.000576)$ & $(0.000653)$ & $(0.000580)$ & $(0.000580)$ & $(0.001400)$ & $(0.001400)$ \\
\hline Observations & $1,683,927$ & $1,681,877$ & $1,681,877$ & $1,683,882$ & $1,683,882$ & 124,188 & 123,855 & 123,855 & 124,185 & 124,185 \\
\hline R-Squared & 0.012 & 0.13 & 0.129 & 0.152 & 0.151 & 0.018 & 0.057 & 0.057 & 0.091 & 0.091 \\
\hline Below age 65 & $-0.0342 * * *$ & $-0.0238 * * *$ & $-0.0239 * * *$ & $-0.0541 * * *$ & $-0.0542 * * *$ & $-0.0328 * * *$ & $-0.0218 * * *$ & $-0.0219 * * *$ & $-0.0393 * * *$ & $-0.0394 * * *$ \\
\hline Robust std. errors & $(0.000275)$ & $(0.000233)$ & $(0.000233)$ & $(0.000686)$ & $(0.000687)$ & $(0.000730)$ & $(0.000624)$ & $(0.000626)$ & $(0.001430)$ & $(0.001440)$ \\
\hline Observations & $1,011,181$ & $1,009,851$ & $1,009,851$ & $1,011,154$ & $1,011,154$ & 88,668 & 88,457 & 88,457 & 88,668 & 88,668 \\
\hline R-Squared & 0.01 & 0.151 & 0.148 & 0.169 & 0.166 & 0.016 & 0.054 & 0.054 & 0.089 & 0.089 \\
\hline Age 65 and over & $-0.0511 * * *$ & $-0.0375 * * *$ & $-0.0377^{* * *}$ & $-0.0832 * * *$ & $-0.0834 * * *$ & $-0.0469 * * *$ & $-0.0328 * * *$ & $-0.0328 * * *$ & $-0.0636 * * *$ & $-0.0636 * * *$ \\
\hline Robust std. errors & $(0.000425)$ & $(0.000371)$ & $(0.000370)$ & $(0.001040)$ & (0.001040) & $(0.001380)$ & $(0.001230)$ & $(0.001230)$ & $(0.003590)$ & $(0.003590)$ \\
\hline Observations & 672,746 & 672,026 & 672,026 & 672,728 & 672,728 & 35,520 & 35,398 & 35,398 & 35,517 & 35,517 \\
\hline R-Squared & 0.016 & 0.112 & 0.112 & 0.142 & 0.142 & 0.024 & 0.069 & 0.068 & 0.125 & 0.125 \\
\hline Controls & & $\boldsymbol{v}$ & $\sqrt{ }$ & $\sqrt{ }$ & $\sqrt{ }$ & & $\boldsymbol{v}$ & $\sqrt{ }$ & $\sqrt{ }$ & $\sqrt{ }$ \\
\hline Age & & & $\boldsymbol{V}$ & & $\boldsymbol{v}$ & & & $\boldsymbol{v}$ & & $\boldsymbol{v}$ \\
\hline Physician Fixed Effect & & & & $\sqrt{ }$ & $\boldsymbol{v}$ & & & & $\mathbf{v}$ & $\sqrt{ }$ \\
\hline
\end{tabular}


Table 7: The effect of splitter status and distance to the nearest acute care hospital on surgical risk selection in Florida ASCs, 2004-2007

Dependent Variable:

All Outpatient Gastrointestinal Endoscopy

Screening Colonoscopy Only

Charlson Score

\begin{tabular}{lllll}
\hline$[1]$ & {$[2]$} & {$[3]$} & {$[4]$} & [5]
\end{tabular}

[6] [7] [8] [9]

[9]

[10]

\begin{tabular}{|c|c|c|c|c|c|c|c|c|c|c|c|}
\hline \multirow{5}{*}{$\begin{array}{l}\frac{0}{0} \\
\frac{0}{\xi} \\
\frac{0}{0} \\
\overline{\bar{J}}\end{array}$} & Splitter & $\begin{array}{c}-0.0227^{* * *} \\
(0.00140)\end{array}$ & $\begin{array}{c}-0.0181^{* * *} \\
(0.00141)\end{array}$ & $\begin{array}{c}-0.0173 * * * \\
(0.00141)\end{array}$ & $\begin{array}{c}-0.0208^{* * *} \\
(0.00143)\end{array}$ & $\begin{array}{c}-0.0220^{* * *} \\
(0.00143)\end{array}$ & $\begin{array}{c}-0.0704^{* * *} \\
(0.00537)\end{array}$ & $\begin{array}{c}-0.0644^{* * *} \\
(0.00510)\end{array}$ & $\begin{array}{c}-0.0641 * * * \\
(0.00511)\end{array}$ & $\begin{array}{c}-0.0412^{* * *} \\
(0.00452)\end{array}$ & $\begin{array}{c}-0.0416^{* * *} \\
(0.00450)\end{array}$ \\
\hline & Distance & $\begin{array}{c}-0.00714^{* * *} \\
(0.00046)\end{array}$ & $\begin{array}{c}-0.00667^{* * *} \\
(0.00046)\end{array}$ & $\begin{array}{c}-0.00649 * * * \\
(0.00046)\end{array}$ & $\begin{array}{c}-0.00220 * * * \\
(0.00052)\end{array}$ & $\begin{array}{c}-0.00249 * * * \\
(0.00052)\end{array}$ & $\begin{array}{c}-0.0229 * * * \\
(0.00177)\end{array}$ & $\begin{array}{c}-0.0191^{* * *} \\
(0.00166)\end{array}$ & $\begin{array}{r}-0.0191 * * * \\
(0.00166)\end{array}$ & $\begin{array}{c}-0.0126^{* * *} \\
(0.00160)\end{array}$ & $\begin{array}{r}-0.0127^{* * *} \\
(0.00159)\end{array}$ \\
\hline & Splitter x Distance & $\begin{array}{c}0.00540 * * * \\
(0.00048)\end{array}$ & $\begin{array}{c}0.00484^{* * *} \\
(0.00048)\end{array}$ & $\begin{array}{c}0.00482^{* * *} \\
(0.00048)\end{array}$ & $\begin{array}{c}0.00284^{* * *} \\
(0.00055)\end{array}$ & $\begin{array}{c}0.00309 * * * \\
(0.00055)\end{array}$ & $\begin{array}{c}0.0208^{* * *} \\
(0.00179)\end{array}$ & $\begin{array}{c}0.0179 * * * \\
(0.00169)\end{array}$ & $\begin{array}{c}0.0178^{* * *} \\
(0.00169)\end{array}$ & $\begin{array}{c}0.0122^{* * *} \\
(0.00168)\end{array}$ & $\begin{array}{c}0.0123 * * * \\
(0.00167)\end{array}$ \\
\hline & Observations & $1,326,337$ & $1,320,921$ & $1,320,921$ & $1,320,921$ & $1,320,921$ & 93,587 & 93,561 & 93,561 & 93,561 & 93,561 \\
\hline & R-Squared & 0.001 & 0.042 & 0.043 & 0.047 & 0.046 & 0.010 & 0.027 & 0.027 & 0.049 & 0.049 \\
\hline \multirow{5}{*}{ 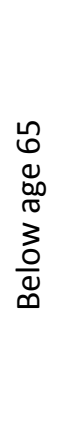 } & Splitter & $\begin{array}{c}-0.0193 * * * \\
(0.00172)\end{array}$ & $\begin{array}{c}-0.0144 * * * \\
(0.00169)\end{array}$ & $\begin{array}{c}-0.0140 * * * \\
(0.00169)\end{array}$ & $\begin{array}{c}-0.0146^{* * *} \\
(0.00171)\end{array}$ & $\begin{array}{c}-0.0153^{* * *} \\
(0.00171)\end{array}$ & $\begin{array}{c}-0.0626 * * * \\
(0.00636)\end{array}$ & $\begin{array}{c}-0.0573 * * * \\
(0.00608)\end{array}$ & $\begin{array}{c}-0.0572^{* * *} \\
(0.00609)\end{array}$ & $\begin{array}{c}-0.0374 * * * \\
(0.00545)\end{array}$ & $\begin{array}{c}-0.0375^{* * *} \\
(0.00544)\end{array}$ \\
\hline & Distance & $\begin{array}{c}-0.00624^{* * *} \\
(0.00061)\end{array}$ & $\begin{array}{c}-0.00547^{* * *} \\
(0.00059)\end{array}$ & $\begin{array}{c}-0.00552^{* * *} \\
(0.00059)\end{array}$ & $\begin{array}{c}-0.00168^{* *} \\
(0.00067)\end{array}$ & $\begin{array}{c}-0.00195^{* * *} \\
(0.00067)\end{array}$ & $\begin{array}{c}-0.0218^{* * *} \\
(0.00231)\end{array}$ & $\begin{array}{c}-0.0187^{* * *} \\
(0.00218)\end{array}$ & $\begin{array}{c}-0.0187^{* * *} \\
(0.00218)\end{array}$ & $\begin{array}{c}-0.0125^{* * *} \\
(0.00201)\end{array}$ & $\begin{array}{c}-0.0126^{* * *} \\
(0.00201)\end{array}$ \\
\hline & Splitter x Distance & $\begin{array}{c}0.00500^{* * *} \\
(0.00063)\end{array}$ & $\begin{array}{c}0.00386^{* * *} \\
(0.00061)\end{array}$ & $\begin{array}{c}0.00393^{* * *} \\
(0.00061)\end{array}$ & $\begin{array}{c}0.00236^{* * *} \\
(0.00072)\end{array}$ & $\begin{array}{c}0.00257^{* * *} \\
(0.00072)\end{array}$ & $\begin{array}{c}0.0199 * * * \\
(0.00233)\end{array}$ & $\begin{array}{c}0.0176^{* * *} \\
(0.00223)\end{array}$ & $\begin{array}{c}0.0176^{* * *} \\
(0.00223)\end{array}$ & $\begin{array}{c}0.0117^{* * *} \\
(0.00211)\end{array}$ & $\begin{array}{c}0.0118^{* * *} \\
(0.00210)\end{array}$ \\
\hline & Observations & 779,966 & 775,684 & 775,684 & 775,684 & 775,684 & 65,411 & 65,390 & 65,390 & 65,390 & 65,390 \\
\hline & R-Squared & 0.002 & 0.052 & 0.053 & 0.056 & 0.055 & 0.008 & 0.022 & 0.022 & 0.04 & 0.04 \\
\hline \multirow{5}{*}{ 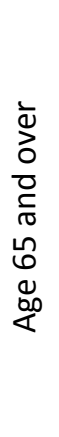 } & Splitter & $\begin{array}{c}-0.0261^{* * *} \\
(0.00229)\end{array}$ & $\begin{array}{c}-0.0213^{* * *} \\
(0.00232)\end{array}$ & $\begin{array}{c}-0.0213^{* * *} \\
(0.00232)\end{array}$ & $\begin{array}{c}-0.0293^{* * *} \\
(0.00239)\end{array}$ & $\begin{array}{c}-0.0297^{* * *} \\
(0.00239)\end{array}$ & $\begin{array}{c}-0.0806^{* * *} \\
(0.00948)\end{array}$ & $\begin{array}{c}-0.0770^{* * *} \\
(0.00918)\end{array}$ & $\begin{array}{c}-0.0775^{* * *} \\
(0.00918)\end{array}$ & $\begin{array}{c}-0.0473^{* * *} \\
(0.00795)\end{array}$ & $\begin{array}{c}-0.0477^{* * *} \\
(0.00796)\end{array}$ \\
\hline & Distance & $\begin{array}{c}-0.00886 * * * \\
(0.00069)\end{array}$ & $\begin{array}{c}-0.00744^{* * *} \\
(0.00069)\end{array}$ & $\begin{array}{c}-0.00741^{* * *} \\
(0.00069)\end{array}$ & $\begin{array}{c}-0.00317^{* * *} \\
(0.00078)\end{array}$ & $\begin{array}{c}-0.00323^{* * *} \\
(0.00078)\end{array}$ & $\begin{array}{c}-0.0221^{* * *} \\
(0.00246)\end{array}$ & $\begin{array}{c}-0.0188^{* * *} \\
(0.00237)\end{array}$ & $\begin{array}{c}-0.0189 * * * \\
(0.00237)\end{array}$ & $\begin{array}{c}-0.0113^{* * *} \\
(0.00249)\end{array}$ & $\begin{array}{c}-0.0114^{* * *} \\
(0.00250)\end{array}$ \\
\hline & Splitter x Distance & $\begin{array}{c}0.00646 * * * \\
(0.00073)\end{array}$ & $\begin{array}{c}0.00556^{* * *} \\
(0.00073)\end{array}$ & $\begin{array}{c}0.00565^{* * *} \\
(0.00073)\end{array}$ & $\begin{array}{c}0.00436^{* * *} \\
(0.00085)\end{array}$ & $\begin{array}{c}0.00434^{* * *} \\
(0.00085)\end{array}$ & $\begin{array}{c}0.0194^{* * *} \\
(0.00254)\end{array}$ & $\begin{array}{c}0.0172^{* * *} \\
(0.00244)\end{array}$ & $\begin{array}{c}0.0173 * * * \\
(0.00244)\end{array}$ & $\begin{array}{c}0.0127^{* * *} \\
(0.00273)\end{array}$ & $\begin{array}{c}0.0128 * * * \\
(0.00273)\end{array}$ \\
\hline & Observations & 546,371 & 545,237 & 545,237 & 545,237 & 545,237 & 28,176 & 28,171 & 28,171 & 28,171 & 28,171 \\
\hline & R-Squared & 0.001 & 0.033 & 0.033 & 0.039 & 0.039 & 0.012 & 0.036 & 0.036 & 0.068 & 0.068 \\
\hline & Controls & & $\sqrt{ }$ & $\boldsymbol{v}$ & $\boldsymbol{v}$ & $\mathbf{v}$ & & $\boldsymbol{v}$ & $\sqrt{ }$ & $\sqrt{ }$ & $\sqrt{ }$ \\
\hline & Age & & & $\mathbf{v}$ & & $\sqrt{ }$ & & & $\mathbf{v}$ & & $\boldsymbol{v}$ \\
\hline & County Fixed Effect & & & & $\sqrt{ }$ & $\sqrt{ }$ & & & & $\begin{array}{lll}\mathbf{v} & & -1\end{array}$ & $\mathbf{v}$ \\
\hline
\end{tabular}

